\title{
C-banded Karyotypes of Seven Cultivars of Oryza sativa
}

\author{
M. A. Hamoud', Y. A. Hassan ${ }^{1}$, W. Nagl ${ }^{2}$ and E. E. Selim ${ }^{1}$ \\ ${ }^{1}$ Botany Department, Faculty of Science, Tanta University, Tanta, Egypt \\ 2Department of Cell Biology, Kaiserslautern University, Kaiserslautern, West Germany
}

Accepted December 13, 1990

Preferential Giemsa staining of heterochromatin has been used as a mean of distinguishing the somatic metaphase chromosomes of several plants. Marks and Schweizer (1974) reporoted considerable inter-specific variations in the karyotypes of six species of Anemone and in Hepatica nobilis, both regarding the amount and distribution of Giemsa C-bands. Filion (1974) also found a wide range in the amount of constitutive heterochromatin; as measured by the amount of banding, between three cultivars of Tulipa. Ramachandran et al. (1985) also found infraspecific variation in C-banding pattern of non-cultivated and cultivated Cucumis sativus accessions. In addition, Giemsa C-banding has been used in the identification of common wheat chromosomes (Endo 1986).

Giemsa C-banding has also been used as a further cytological tool to verify both generic and specific delimitation of many plants. It has also been proved valuable in providing evidence for the taxonomic arrangement of Scilla and Puschkinia (Greilhuber and Speta 1976, 1978), Anacyclus (Schweizer and Ehrendorfer 1976), Nigella (Gilot-Dehale et al. 1976) and Allium (Badr and Elkingtonn 1977, 1984, Elgadi and Elkington 1975, Elkington et al. 1976, Vosa 1976a, b).

Until recently such studies were lacking in rice because of its small chromosomes which have been difficult to obtain in a good cytological preparation. Kurata (1987) investigated the morphological characteristics of rice chromosomes in mitosis and meiosis. He studied centromere position, relative chromosome length, nucleolous organizing regions as well as darkly stained chromosome segments in the strain japonica of Oryza sativa, O. perenus, O. punctate and $O$. officinalis by the aid of Giemsa stain. Some other cytological studies were also carried out on rice (Shastry et al. 1960, Wu 1967, Misra and Shastry 1967, Ranganadhacharyulu and Raj 1974, Khan 1975, Reddi and Reddi 1977, Dolores et al. 1977, Sato et al. 1980, Wu and Chung 1986). We present here the C-banding patterns in seven cultivars of Oryza sativa being cultivated in Egypt. Their relative chromosome lengths and arm ratios are also included.

\section{Materials and methods}

The seven cultivars used for this study from Oryza sativa L. were obtained as grains from the Agricultural Research Centre, Cairo, A. R. Egypt. These cultivars are: Sabene, IR 28, Reiho, Giza 159, Giza 171, Giza 172 and Giza 175.

Root tips were taken from grains germinated at room temperature $\left(24^{\circ}-28^{\circ} \mathrm{C}\right)$ on moist filter papers in glass petri dishes. The procedure used for Giemsa banding; a modification from that of Gostev and Asker (1978); can be summarized as follows:

Pretreatment: Root tips. $0.5-1.5 \mathrm{~cm}$ long, were pretreated with a solution of $2 \mathrm{mM}$ 8-hydroxyquinoline for $3 \mathrm{hr}$ at room temperature.

Fixation: Root tips were then washed with distilled water and fixed in a freshly prepared mixture of absolute alcohol/glacial acetic acid $(3: 1 \mathrm{v} / \mathrm{v})$ at room temperature for $24 \mathrm{hr}$, then- 
after, they were washed and stored in $70 \%$ ethanol in refrigerator until use.

Maceration: Root tips were treated with an enzyme mixture of $6 \%(\mathrm{~W} / \mathrm{V})$ pectinase and $2 \%(\mathrm{~W} / \mathrm{V})$ cellulase in $0.01 \mathrm{M}$ citrate buffer, $\mathrm{pH} 4.6$, for $4 \mathrm{hr}$ at $37^{\circ} \mathrm{C}$ (The buffer was prepared from a ten times concentrated stock solution consisting of three parts of $0.1 \mathrm{M}$ trisodium citrate and two parts of $0.1 \mathrm{M}$ citric acid).

Squash: The meristematic parts were cut off and transfered to a small drop of $45 \%$ acetic acid on a clean slide. The contents of the meristematic piece were then pressed out to form a cell suspension, then covered with clean cover slip and squashed cautionsly without heating. Dehydration: The cover slip was separated from the slide by using a flexi-cool plate. Slides were immersed briefly in absolute alcohol and then air dried. In order to obtain good resolution of bands, slides were incubated for 1 or 2 days at $40-45^{\circ} \mathrm{C}$.

Denaturation: The slides were immersed in $5 \%(\mathrm{~W} / \mathrm{V}) \mathrm{Ba}(\mathrm{OH})_{2}$ for $10 \mathrm{~min}$ at room temperature and then washed in running tap water for 15-60 min.

Renaturation: Slides were kept in $2 \times \mathrm{SSC}$ (Sodium Saline Citrate) at $60^{\circ} \mathrm{C}$ for one $\mathrm{hr}$, washed in distilled water and then $1 / 15 \mathrm{M}$ Sorensen phosphaste buffer, $\mathrm{pH} 6.8$, which was prepared as a mixure of $1 / 15 \mathrm{M} \mathrm{KH}_{2} \mathrm{PO}_{4}$ and $1 / 15 \mathrm{M} \mathrm{Na}_{2} \mathrm{HPO}_{4} \cdot 2 \mathrm{H}_{2} \mathrm{O}$.

Staining: Staining of slides was carried out for $3 \mathrm{hr}$ in $2 \%$ Giemsa (Merch) prepared in $1 / 15 \mathrm{M}$ Sorensen phosphate buffer ( $\mathrm{pH}$ 6.8). Then, slides were briefly washed in buffer and air dried.

Mounting: Mounting was carried out in Euparal TM and slides were left to dry at $60^{\circ} \mathrm{C}$ overnight.

The slides were examined under light microscope at a magnification of $1000 \times$ using oil immersion. Well stained configurations of chromosomes were photographed using Agfa Ortho black-white film and idiograms were then constructed on tracing paper. The number and size of chromosomes as well as heterochromatic bands were also recorded.

\section{Results}

Results of chromosome relative length (RL) and arm ratios (AR) of the seven Oryza sativa cultivars are given in Table 1 . These results show that the karyotype of $O$. sativa is constructed of five metacentric (mc); K3, K6, K7, K8 and $\mathrm{K} 11$; five submetacentric (sm; $\mathrm{Kx}, \mathrm{K} 2, \mathrm{~K} 5, \mathrm{~K} 9$ and $\mathrm{K} 12$ and two subtelocentric (st); K4 and K10; chromosome pairs. These results are similar to those obtained by Kurata (1987) and Kurata and Omura (1978). However, they recorded one chromosome pair, $\mathrm{K} 10$, with nucleolar organizer.

The idiograms of Giemsa C-banded complements of different cultivars are presented in Figs. 1-7.

\section{Sabene: Fig. 1.}

This cultivar exhibits a low amount of constitutive heterochromatin in its genome. All $\mathrm{mc}$ and sm chromosomes have centrometric bands except $\mathrm{K} 11$ which is not banded and $\mathrm{K} 12$ which has telomeric band on the short arm. The st chromosome type K4, however, has a telomeric band on the short arm while the other st type $\mathrm{K} 10$ shows two telomeric bands on both arms.

IR 28: Fig. 2.

The three sm chromosome types $\mathrm{K} 1, \mathrm{~K} 2$ and $\mathrm{K} 9$ show interstitial bands on their long arms while $\mathrm{K} 5$ and $\mathrm{K} 12$ exhibit centrometric bands. The only banded mc chromosome types are $\mathrm{K} 3$ which has two interstital bands on its long arm, and K11 which has centromeric band. However, the other me chromosome types $\mathrm{K} 6, \mathrm{~K} 7$ and $\mathrm{K} 8$ are not banded. The at chromo- 
somes $\mathrm{K} 4$ and $\mathrm{K} 10$ have two thick bands each, on both short and long arms with bands covering the whole short, and most of the long arms of the latter type.

Reiho: Fig. 3.

The sm chromosomes types $\mathrm{K} 2$ and $\mathrm{K} 5$ exhibit centrometric bands, while $\mathrm{K} 1$ has one interstitial band on each arm. The other two types $\mathrm{K} 9$ and $\mathrm{K} 12$, however, show no bands. The mc types K3, K7 and K11 also have interstitial band on each of their arms whereas the two types $\mathrm{K} 6$ and $\mathrm{K} 8$ are not banded. On the other hand, the two st types $\mathrm{K} 4$ and $\mathrm{K} 10$ have similar appearance of bands. Their whole short arms are banded while long arms have an intercalary band each.

Table 1. Means of chromosome relative length (RL) and arm ratio (AR) in seven cultivars of Oryza sativa

\begin{tabular}{|c|c|c|c|c|c|c|c|c|c|c|c|c|c|c|}
\hline \multirow{2}{*}{$\begin{array}{l}\text { Chromosome } \\
\text { Type }\end{array}$} & \multicolumn{2}{|c|}{ Sabene } & \multicolumn{2}{|c|}{ IR 28} & \multicolumn{2}{|c|}{ Reiho } & \multicolumn{2}{|c|}{ Giza 159} & \multicolumn{2}{|c|}{ Giza 171} & \multicolumn{2}{|c|}{ Giza 175} & \multicolumn{2}{|c|}{ Giza 172} \\
\hline & RL & AR & RL & AR & $\mathbf{R L}$ & $\mathrm{AR}$ & RL & AR & RL & AR & $\mathrm{RL}$ & AR & $\mathrm{RL}$ & AR \\
\hline K 1 & 13.90 & 1.75 & 12.40 & 1.88 & 11.80 & 1.80 & 13.30 & 1.95 & 12.60 & 1.78 & 13.90 & 1.78 & 12.00 & 1.85 \\
\hline K 2 & 12.50 & 2.15 & 10.10 & 2.10 & 10.70 & 2.16 & 12.60 & 2.30 & 12.00 & 2.33 & 12.50 & 2.30 & 11.50 & 1.91 \\
\hline K 3 & 9.70 & 1.33 & 9.30 & 1.33 & 9.60 & 1.36 & 10.10 & 1.40 & 11.00 & 1.50 & 10.80 & 1.30 & 9.40 & 1.25 \\
\hline K 4 & 8.30 & 3.67 & 9.30 & 3.75 & 8.80 & 4.28 & 8.40 & 4.33 & 10.30 & 3.88 & 8.40 & 3.67 & 9.40 & 3.70 \\
\hline K 5 & 8.30 & 2.10 & 8.70 & 2.16 & 8.30 & 2.05 & 8.40 & 2.20 & 9.00 & 2,00 & 8.40 & 2.00 & 8.10 & 2.00 \\
\hline K 6 & 7.60 & 1.17 & 8.20 & 1.13 & 8.30 & 1.11 & 7.70 & 1.08 & 7.30 & 1.14 & 7.00 & 1.08 & 8.10 & 1.20 \\
\hline K 7 & 7.30 & 1.30 & 7.60 & 1.40 & 8.30 & 1.25 & 7.00 & 1.22 & 6.60 & 1.40 & 7.00 & 1.25 & 7.70 & 1.40 \\
\hline K 8 & 6.90 & 1.25 & 7.60 & 1.20 & 8.00 & 1.15 & 7.00 & 1.18 & 6.60 & 1.11 & 7.00 & 1.10 & 7.70 & 1.20 \\
\hline K 9 & 6.90 & 1.75 & 7.60 & 1.83 & 8.00 & 1.80 & 7.00 & 1.78 & 6.60 & 1.75 & 7.00 & 1.75 & 7.30 & 1.77 \\
\hline K10 & 6.90 & 3.80 & 7.30 & 4.33 & 7.00 & 4.40 & 6.30 & 4.80 & 6.30 & 4.00 & 7.00 & 4.00 & 6.80 & 3.96 \\
\hline $\mathrm{K} 11$ & 5.90 & 1.28 & 6.20 & 1.17 & 5.90 & 1.17 & 6.30 & 1.21 & 6.00 & 1.20 & 5.60 & 1.30 & 6.00 & 1.33 \\
\hline $\mathrm{K} 12$ & 5.60 & 2.45 & 5.60 & 2.33 & 5.30 & 2.33 & 5.90 & 2.33 & 5.60 & 2.22 & 5.60 & 2.30 & 5.60 & 2.19 \\
\hline $\begin{array}{l}\text { Total } \\
\text { Genome }(\mu \mathrm{m})\end{array}$ & 28. & .80 & & 50 & & 40 & & 60 & & .10 & & .70 & & 0 \\
\hline $\begin{array}{l}\text { Mean } \\
\pm S . E .\end{array}$ & $\begin{array}{r}2 . \\
\pm 0 .\end{array}$ & $\begin{array}{l}.40 \\
.21\end{array}$ & $\begin{array}{r}2 . \\
\pm 0\end{array}$ & & $\begin{array}{r}3 . \\
\pm 0\end{array}$ & $\begin{array}{l}12 \\
20\end{array}$ & $\begin{array}{r}2 . \\
\pm 0 .\end{array}$ & & $\begin{array}{r}2 . \\
\pm 0\end{array}$ & $\begin{array}{l}51 \\
22\end{array}$ & $\begin{array}{r}2 . \\
\pm 0\end{array}$ & $\begin{array}{l}39 \\
.22\end{array}$ & $\begin{array}{r}1 \\
\pm 0\end{array}$ & $\begin{array}{l}95 \\
13\end{array}$ \\
\hline
\end{tabular}

Giza 159: Fig. 4.

In this cultivar two bands are exhibited by each of the sm types $\mathrm{K} 1, \mathrm{~K} 2$ and $\mathrm{K} 5$, the mc types $\mathrm{K} 3$ and $\mathrm{K} 7$, and the st type $\mathrm{K} 10$. The chromosome types K1, K5, K7 and $\mathrm{K} 10$ have their bands distributed on their two arms while K2 and K3 have the two bands on their long arms only. A single band however is exhibted by the st type $\mathrm{K} 4$ on telomere of the short arm and by the sm type $\mathrm{K} 9$ on its centromere. The other mc types, $\mathrm{K} 6, \mathrm{~K} 8, \mathrm{~K} 11$ and the sm type $\mathrm{K} 12$ are not banded.

\section{Giza 171: Fig. 5.}

The sm types K1 and K2 have two intercalary bands each, one on either arms of the former and the two on the long arm only of the latter. The two sm types $\mathrm{K} 5$ and $\mathrm{K} 9$ however, have single intercalary band each, on their long arms while $\mathrm{K} 12$ has centrometric band. The only banded mc chromosome type is $\mathrm{K} 3$ which has two intercalary bands on both arms while the other types $\mathrm{K} 6, \mathrm{~K} 7, \mathrm{~K} 8$ and $\mathrm{K} 11$ are not banded. Both the st types $\mathrm{K} 4$ and $\mathrm{K} 10$ have their short arms fully banded with the former having another two intercalary bands on its long arm.

Giza 175: Fig. 6.

The five longest chromosome types $\mathrm{K} 1, \mathrm{~K} 2, \mathrm{~K} 3, \mathrm{~K} 4$ and $\mathrm{K} 5$ of this cultivar are similar in 
their band positions to those of the previous one. The shortest chromosome type $\mathrm{K} 12$ is also similar to its counterpart in the previosu cultivar in having centrometric band. The three mc types $\mathrm{K} 6, \mathrm{~K} 7$ and $\mathrm{K} 8$ which are not banded in Giza 171 are banded in this cultivar and have single intercalary band on the short arm of the former two types (K6 and K7) and two intercalary bands on both arms of the latter type (K8). The sm type K9 which has single intercalary
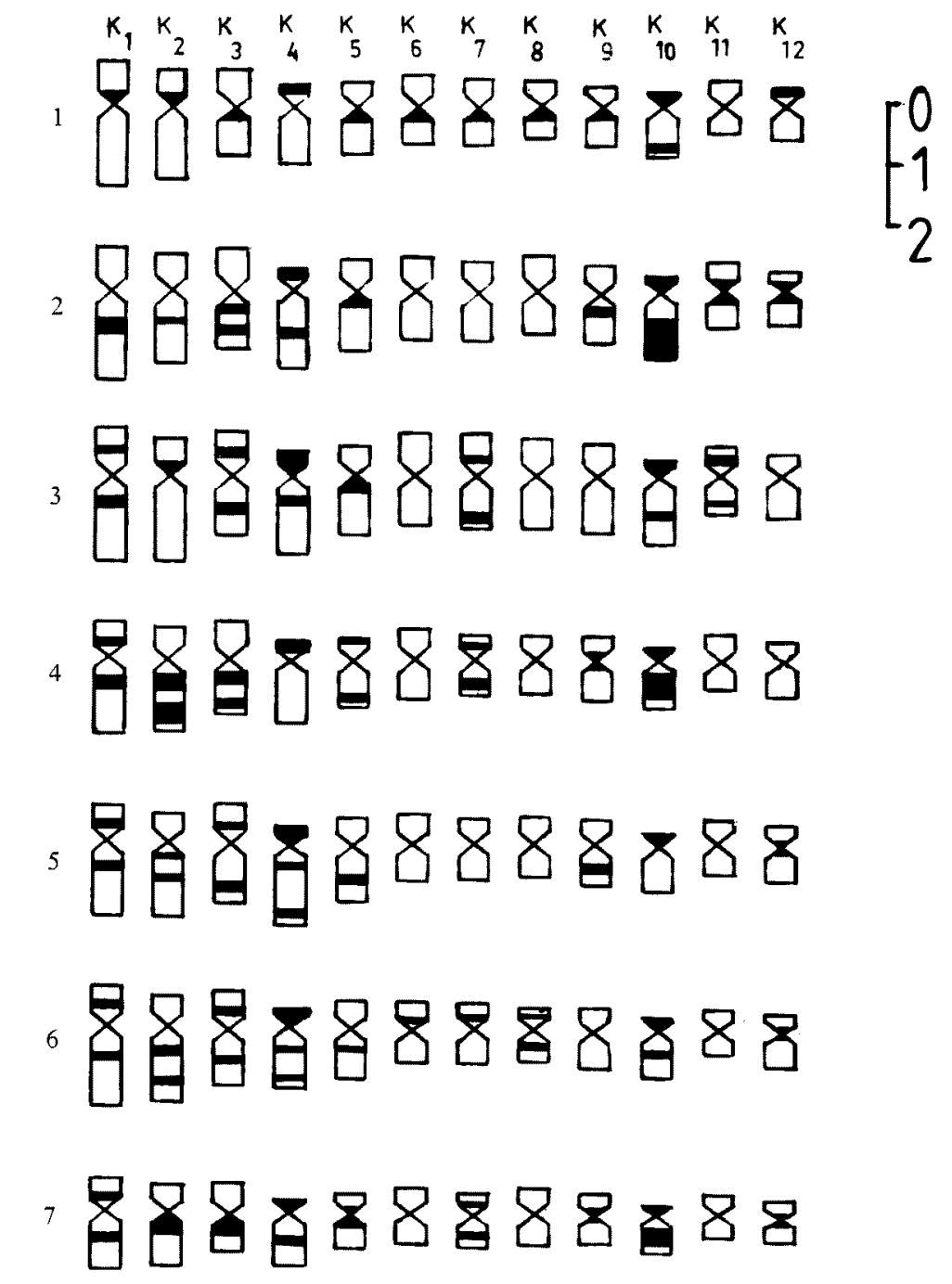

Figs. 1-7. Idiograms of Giemsa C-banded karyotypes of seven cultivars of Oryza sativa. 1, Sabene. 2, IR 28. 3, Reiho. 4, Giza 159. 5, Giza 171. 6, Giza 175 and 7, Giza 172.

band on its long arm in Giza 171, however, is not banded in this cultivar while the st type K10 has one intercalary band on its long arm in addition to the band observed on the short arm.

Giza 172: Fig. 7.

The sm chromosome type $\mathrm{K} 1$ has two intercalary bands, one on each arm, whereas the other sm types $\mathrm{K} 2, \mathrm{~K} 5, \mathrm{~K} 9$ and $\mathrm{K} 12$ have single centromeric band each. Also the mc type K7 has two intercalary bands, one on each arm, and K3 has single centromeric band whereas the 
other mc types; K6, K8 and K11; exhitbit no bands. However, the two st types $\mathrm{K} 4$ and $\mathrm{K} 10$ are similar in having their short arms fully banded and having single intercalary band on their long arms.

\section{Discussion}

The present study on mitotic chromosomes of seven Oryza sativa cultivars shows that total genome size varies from relatively high in Reiho $(37.4 \mu \mathrm{m})$ to relatively small in Giza $172(23.4$ $\mu \mathrm{m})$. It ranges in the other five cultivars between 28.7 and $35.5 \mu \mathrm{m}$. In spite of these variations, the genome of each cultivar is identifiable into twelve distinguished chromosome types. These are designated K1 to K12 according to their length (Kurata 1987, Kurata and Omura 1978).

The results also show that the genome of $O$. sativa is considerably rich in heterochromatin with intraspecific variation in C-banding patterns. Karyotypic variation may involve linear amplification or deletion of specific repetitive sequences, translocation and invesrion of chromosome segments, or unequal crossing over (Rees and Jones 1972, Hutchinson et al. 1977). Kurata (1987) and Kurata et al. (1981) observed; in rice; several bands distributed all along the chromosome which decreased in number with the advancement of stage. These bands showed the characteristics of the G-bands reported in other organsims (Yunis and Sanchez 1973, Yunis

Table 2. Collective frequency of C-bands in different chromosome types of seven cultivars of Oryza sativa

\begin{tabular}{lccccccccccccc}
\hline \hline $\begin{array}{c}\text { Chromosome } \\
\text { Type } \\
\text { Band type }\end{array}$ & $\begin{array}{c}\mathrm{K} 1 \\
\mathrm{sm}\end{array}$ & $\begin{array}{c}\mathrm{K} 2 \\
\mathrm{sm}\end{array}$ & $\begin{array}{c}\mathrm{K} 3 \\
\mathrm{mc}\end{array}$ & $\begin{array}{c}\mathrm{K} 4 \\
\mathrm{st}\end{array}$ & $\begin{array}{c}\mathrm{K} 5 \\
\mathrm{sm}\end{array}$ & $\begin{array}{c}\mathrm{K} 6 \\
\mathrm{mc}\end{array}$ & $\begin{array}{c}\mathrm{K} 7 \\
\mathrm{mc}\end{array}$ & $\begin{array}{c}\mathrm{K} 8 \\
\mathrm{mc}\end{array}$ & $\begin{array}{c}\mathrm{K} 9 \\
\mathrm{sm}\end{array}$ & $\begin{array}{c}\mathrm{K} 10 \\
\mathrm{st}\end{array}$ & $\begin{array}{c}\mathrm{K} 11 \\
\mathrm{mc}\end{array}$ & $\begin{array}{c}\mathrm{K} 12 \\
\mathrm{sm}\end{array}$ \\
\hline Telomeric & - & - & - & 7 & 1 & - & - & - & - & 8 & - & 1 \\
Centromeric & 1 & 3 & 2 & - & 4 & 1 & 1 & 1 & 3 & - & 1 & 4 \\
Interstitial & 11 & 7 & 10 & 7 & 3 & 1 & 7 & 2 & 2 & 5 & 2 & - \\
\hline
\end{tabular}

et al. 1978). In the present study, however, the C-bands observed in metaphase chromosomes showed a high degree of stability. The number of bands per chromosome ranges from zero to three at the most with some variation in their size. The subtelocentric chromosomes K4 and K10 are identifiable with their wholly banded short arms in all cultivars. In Sabene, most of the chromosomes show single centromeric band and terminal bands are sometimes observed. An intercalary band is recorded in this cultivar only on the long arm of the st chromosome type K10. On the other hand, the other cultivars show less centromeric and high interstitial and terminal bands. The highest number of interstitial bands is exhibited by the chromosomes of Giza 175 (14 bands) followed by Reiho, Giza 159 and Giza 171 (10 bands each). Hsu (1973) interpreted the interstitial and terminal C-bands, and the lack of centromeric bands, as being a result of inversions or translocations. This interpretation seems to fit the case in these cultivars of $O$. Sativa.

The present study shows infraspecific differences in C-band patterns among the seven cultivars investigated of Oryza sativa. The highest frequency of bands, collectively in the seven cultivars, has been recorded (Table 2) in the subtelocentric chromosomes $\mathrm{K} 4$ and $\mathrm{K} 10$. These two chromosome types exhibit high frequencies of telomeric and interstitial bands with no centromeric ones. The longest three chromosome types $\mathrm{K} 1, \mathrm{~K} 2$ and $\mathrm{K} 3$ display high frequencies in interstitial bands with frequent centromeric bands and no telomeric ones. The two metacentric chromosome type $\mathrm{K} 8$ and $\mathrm{K} 11$ are often not banded in the cultivars investigated. 


\section{Summary}

Seven cultivars of Oryza sativa, being grown in Egypt, have been cytologically investigated with the aid of Giemsa C-banding technique. These cultivars are Sabene, IR 28, Reiho, Giza 159, Giza 171, Giza 172 and Giza 175. All these cultivars have karotypes that constructed from five meta-, five submeta- and two subtelo-centric chromosome pairs. The lowest value for total genome size; $23.4 \mu \mathrm{m}$; was recorded in Giza 172 and the highest; $37.4 \mu \mathrm{m}$; was recorded in Reiho. The other cultivars showed genomes that ranged between 28.6 and $30.1 \mu \mathrm{m}$, except IR 28 which exhibited genome size of $35.5 \mu \mathrm{m}$. The results also showed that the genome of $O$. sativa is considerably rich in heterochromatin with variation in C-banding pattern among the different cultivars. The frequency of telomeric and interstatial bands was very high in the subtelocentric type of chromosomes which exhibited no centromeric bands. On the other hand, interstatial bands were recorded in high numbers in the longest meta- and submetacentric chromosomes which frequently exhibited centrometric bands.

\section{References}

Badr, A. and Elkington, T. T. 1984. Giemsa C-banded Karyotypes and Taxonomic relationships of some North American Allium species and their relationships to Old World species (Liliaceae). PI. Syst. Evol. 144: 17-24.

- and - 1977. Giemsa C-band and fluorochrome banded Karyotypes and species relationships in Allium subgenus Molium. Ibid 128: 23-35.

Dolores, R. C., Chang, T. T. and Ramirez, D. A. 1979. The cytogenetics of $F_{1}$ hybrids from Oryza nivara Sharma et Shastry $\times O$. sativa L. Cytologia 44: $527-540$.

El-Gadi, A. and Elkington, T. T. 1975. Comparison of the Giemsa C-band karyotypes and the relationships of Allium cepa, A. fistulosum, and A. galanthum. Chromosoma 51: 19-23.

El Kington, T. T., Badr, A., Hussain, L. and White, S. 1976. Giemsa C-band and quinacrine banded karyotypes and systematic relationships in Allium. In Jones, K., Barndham, P. E. (eds.): Current chromosome Research, 214-215. North Holland Press.

Endo, T. R. 1986. Complete identification of common wheat chromosomes by means of the C-banding technique. Jpn. J. Genet. 61: 89-93.

Filion, W. G. 1974. Differential Giemsa staining in plants I. Banding patterns in three cultivars of Tulipa. Chromosoma 49: 51-60.

Gilot-Delhale, J., Degraeve, N. and Moutschen, J. 1976. Cytotaxonomic investigations of the genus Nigella (Helleboreae) with C-banding techniques. Caryologia 29: 139-154.

Gostev, A. and Asker S. 1979. A C-banding technique for small plant chromosomes. Hereditas 91: 140-143.

Greilhuber, J. and Speta, F. 1976. C-banded Karyotypes in the Scilla hohenackeri group, S. persica and Puschkinia (Liliaceae). Pl. Syst. Evol. 126: 149-188.

- and - 1978. Quantitative analysis of C-banded karyotypes and systematics in the cultivated species of the Scilla siberica group (Liliaceae). Ibid. 129: 63-109.

Hsu, T. C. 1973. Longitudind differentiation of chromosomes. Ann. Rev. Genet. 7: 153-176.

Hutch inson, J., Narayan, R. K. and Rees, H. 1977. Constraints upon the composition of supplementary DNA. Chromosoma 78 : 137-145.

Khan, S. H. 1975. A technique for staining rice chromosomes. Cytologia 40: 595-598.

Kurata, N. 1987. Chromosome analysis of mitosis and meiosis in rice. Rice Genet., Japan; 143-152.

- and Omura T. 1978. Karyotype analysis in rice. I. A new method for identifying all chromosome pairs. Jpn. J. Genet. 56: 251-255.

-, Iwata, N. and Omura T. 1981. Karyotype analysis in rice. II-Identification of extrachromosomes in trisomic plants and banding structure on some chromosomes. Ibid 56: 41-55.

Marks, G. E. and Schweizer, D. 1974. Giemsa banding: Karyotype differences in some species of Anemone and Hepatica nobilis. Chromosoma (Berl.) 44: 405-416.

Misra, R. N. and Shastry, S. V. S. 1967 . Pachytene analysis in Oryza. 8. Chromosome morphology and karyotypic variation in Oryza sativa L. J. Genet PI. Breed. 27: 349-368.

Ramachandran, C., Brandenburg, W. A. and den Nijs, A. P. M. 1985. Infraspecific variation in C-banded karyotype and chiasma frequency in Cucumis sativus (Cucurbitaceae). Plant Syst. Evol, 151: 31-41. 
Ranganadhacharyulu, N. and Raj, A. Y. 1974. Pachytene analysis in an interspecific hybrid Oryza punctata Koschy ex steud $\times O$. eicheingeri A. peter. Cytologia 39: 233-243.

Reddi, V. R. and Reddi, T. V. V.S. 1977. Chromosome pairing at pachytene and meiosis in autotetraploid rice. Cytologia 42: 189-196.

Rees, H. and Jones, R. N. 1972. The origin of the wide species variation in nuclear DNA content. Int. Rev. Cytol. 32: 53-92.

Sato, S., Kinoschita, T. and Takahashi, E. M. 1980. Location of centromere and interchange breakpoints in the pachytene chromosome of rice. Jpn. J. Breed. 30: 387-398.

Schweizer, D. and Ehrendorfer, F. 1976. Giemsa banded karyotypes, systematics, and evolution in Anacyclus (Asteraceae-Anthemideae). Plant syst. Evol. 126: 107-148.

Shastry, S. V. S., Ranga Rao, D. R. and Misra, R. N. 1960. Pachytene analysis in Oryza sativa. Indian J. Genet. Pl. Breed. 20 : 15-21.

Vosa, C. G. 1976a. Heterochromatic patterns in Allium: I. The relationship between the species of the cepa group and its allies. Heredity $36: 383-392$.

- 1976b. Heterochromatic patterns in Allium: II. Heterochromatin variation in species of the paniculatum group. Chromosoma 57: 119-133.

Yunis, J. J. and Sanchez, O. 1973. G-banding and chromosome structure. Chromosoma (Berl.) 44: 15-23.

-, Sawyer, J. R. and Ball, D. W. 1978. The characterization of higher resolution G-banded chromosomes of man. Chromosoma 67: 293-307.

Wu, H. K. 1967. Note on preparing of pachytene chromosomes by double mordant. Scientific Agric. 15: 40-44.

- and Chung, M. C. 1986. Rice karyotype analysis. Proc. Int. Rice Genetic Symp. May 1985, IRRI Manila, Philippines, pp. 135-142. 